\title{
Prevalence and characteristics of brain arteriovenous malformations in hereditary hemorrhagic telangiectasia: a systematic review and meta-analysis
}

\author{
Waleed Brinjikji, MD, ${ }^{1}$ Vivek N. lyer, MD, MPH, ${ }^{2}$ Christopher P. Wood, MD, ${ }^{1}$ and \\ Giuseppe Lanzino, MD ${ }^{3}$
}

Departments of ${ }^{1}$ Radiology, ${ }^{2}$ Pulmonary and Critical Care Medicine, and ${ }^{3}$ Neurosurgery, Mayo Clinic, Rochester, Minnesota

OBJECTIVE Patients with hereditary hemorrhagic telangiectasia (HHT) are known to suffer from high rates of cerebral arteriovenous malformations (AVMs). The authors performed a systematic review and meta-analysis of the literature examining prevalence rates, characteristics, and clinical presentation of cerebral AVMs in the HHT population.

METHODS To identify studies on AVM prevalence and characteristics in the HHT population, 4 databases (MEDLINE, EMBASE, Scopus and Web of Science) were searched by a reference librarian with over 30 years experience in systematic reviews and meta-analysis. The search period was January 1, 1990-March 2016. The following search terms were used: hereditary hemorrhagic telangiectasia, Osler-Weber-Rendu syndrome, AVM, brain AVM, arteriovenous malformation, arteriovenous fistula, prevalence, and epidemiology. The authors identified studies that examined the prevalence rates, characteristics, and clinical presentation of cerebral AVMs in patients with HHT. They assessed overall AVM prevalence rates as well as prevalence rates by age, sex, HHT type, and country/region. They also systematically reviewed the characteristics of AVMs, including rupture status, location, clinical presentation, angioarchitecture, and Spetzler-Martin grade. Data were analyzed using a random-effects meta-analysis model.

RESULTS Thirty-nine studies were included in this meta-analysis. Thirty studies examined brain AVM prevalence rates in various HHT patient populations, and 18 studies examined AVM clinical and angiographic characteristics (9 studies examined both prevalence rates and AVM characteristics). The prevalence of brain AVMs in HHT patients was $10.4 \%$ $(95 \% \mathrm{Cl} 7.9 \%-13.0 \%)$ with no significant difference between males (8.5\%, $95 \% \mathrm{Cl} 4.9 \%-12.0 \%)$ and females $(11.0 \%$, $95 \% \mathrm{Cl} 5.9 \%-16.1 \%)$. Patients with HHT Type 1 (HHT1) had a significantly higher brain AVM prevalence $(13.4 \%, 95 \%$ Cl 9.5\%-17.4\%) compared with those with HHT Type 2 (HHT2) $(2.4 \%, 95 \% \mathrm{Cl} 1.0 \%-3.8 \%)(p<0.0001)$. In $55.2 \%(95 \%$ $\mathrm{Cl} 38.3 \%-72.1 \%)$ of cases, the AVMs were symptomatic. Spetzler-Martin grade was 2 or less in $86.9 \%(95 \% \mathrm{Cl} 67.5 \%-$ $95.2 \%)$ of patients.

CONCLUSIONS The prevalence of brain AVMs in the HHT population is about $10 \%$. HHT1 patients are significantly more likely to have brain AVMs than HHT2 patients. Most AVMs in the HHT population are symptomatic. The SpetzlerMartin grade for these lesions is 2 or less in nearly $90 \%$ of patients.

https://thejns.org/doi/abs/10.3171/2016.7.JNS16847

KEY WORDS arteriovenous malformation; hereditary hemorrhagic telangiectasia; stroke; vascular disorders

$\mathrm{H}$ EREDITARY hemorrhagic telangiectasia (HHT) is an autosomal-dominant disorder affecting vascular beds in multiple organ systems. Pathognomonic vascular lesions in HHT include arteriovenous malformations (AVMs) and telangiectasias of the skin, mucous membranes, and visceral organs (including the lung, liver, and gastrointestinal tract), brain, and spinal cord. ${ }^{37}$ Patients are diagnosed with definite HHT if they meet at least 3 of the 4 Curacao criteria ${ }^{44}$-including 1) spontaneous and recurrent epistaxis, 2) mucocutaneous telangiectasias (lips, oral cavity, face, and fingers) 3) visceral (or CNS) AVMs (brain, liver, gastrointestinal, lung, etc.), and 4) diagnosis of HHT in a first-degree relative using the same criteria.

Over the past 2 decades, genetic studies have success-

ABBREVIATIONS AVF = arteriovenous fistula; $A V M=$ arteriovenous malformation; $H H T=$ hereditary hemorrhagic telangiectasia; $H H T 1=H H T$ Type $1 ; H H T 2=H H T$ Type 2. SUBMITTED April 4, 2016. ACCEPTED July 8, 2016.

INCLUDE WHEN CITING Published online October 21, 2016; DOI: 10.3171/2016.7.JNS16847. 
fully isolated the genes responsible for more than $95 \%$ of definite HHT cases. These mutations affect the TGF$\beta$ signaling pathway leading to downstream changes in vascular cell proliferation which ultimately result in the formation of telangiectasias and arteriovenous malformations (AVMs) in multiple organ systems, including the brain. The major genetic loci associated with HHT include the endoglin gene (ENG, chromosomal location 9q34), mutations of which result in HHT Type 1 (HHT1); the ACVRL1 gene (ALK1, chromosomal location12q13), mutations of which result in HHT Type 2 (HHT2); and the MADH4 gene (SMAD4, chromosomal location 18q21), mutations of which result in the combined syndrome of juvenile polyposis and HHT (JP/HHT).

HHT patients can present with a variety of CNS complications, including vascular malformations of the brain. Over the past several decades, there has been increasing interest in studying the prevalence of brain AVMs in the HHT population as well as their associated clinical presentation and angioarchitectural characteristics. ${ }^{6,7}$ To better understand the prevalence, clinical presentation, and characteristics of brain AVMs in the HHT population, we performed a systematic review and meta-analysis of large case series and population-based studies. The aims of the present study were 1) to determine the overall prevalence of brain AVMs in the HHT population, 2) to investigate prevalence rates by demographic characteristics and HHT type, 3) to examine the clinical presentation of AVMs in HHT patients (including rupture status and symptomatic status), and 4) to study the imaging and angioarchitectural characteristics of brain AVMs in the HHT population.

\section{Methods \\ Literature Search}

For this study we followed the PRISMA (Preferred Reporting Items for Systematic Reviews and Meta-Analyses) recommendations. To identify studies on AVM prevalence and characteristics in the HHT population, 4 databases (MEDLINE, EMBASE, Scopus, and Web of Science) were searched by a reference librarian with over 30 years of experience in systematic reviews and meta-analysis. The search covered the period from January 1, 1990, to March 2016. The following search terms were used: hereditary hemorrhagic telangiectasia, Osler-Weber-Rendu syndrome, AVM, brain AVM, arteriovenous malformation, arteriovenous fistula, prevalence, and epidemiology. For MEDLINE/EMBASE, we used the following search terminology: hereditary hemorrhagic telangiectasia.mp., osler weber rendu.mp., exp Arteriovenous Malformations, exp brain. For Scopus we used the following search terminology: (TITLE-ABS-KEY ((osler W/3 (rendu OR weber)) OR "hereditary haemorrhagic telangiectasia*" OR "hereditary hemorrhagic telangiectasia*") AND TITLE-ABS-KEY ((brain AND (avm OR avms OR (av W/2 (malformation* OR fistula*)) OR arteriovenous)))). For Web of Science we used the following search terminology: (((Osler SAME (rendu OR weber)) OR "hereditary h\#emorrhagic telangiectasia*")) AND TOPIC: (brain AND (avm OR avms OR (av NEAR (malformation* OR fistula*)) OR arteriovenous)). We also searched references from multiple articles to find any additional studies on the prevalence and characteristics of brain AVMs in the HHT population.

We then screened all abstracts and titles of the articles retrieved from the literature search. We then retrieved the full-text publications of all studies that passed the first screen. Studies were assigned to one or both of the following categories: 1) those that looked at brain AVM prevalence rates and 2) those that looked specifically at AVM imaging and clinical characteristics or both. Separate meta-analyses were performed for each of these categories. Inclusion criteria for the studies included in the brain AVM prevalence study meta-analysis were the following: 1) consecutive series of at least 10 patients with brain imaging studies performed on all patients in the study to evaluate for AVMs and 2) patients with definite or probable HHT (meeting at least 2 of the Curacao criteria) or those with a genetic test confirming HHT. Inclusion criteria for studies included in the brain AVM clinical characteristics meta-analysis were the following: 1) consecutive series of at least 5 HHT patients with confirmed brain AVMs and 2) description of rupture status, clinical presentation, and angiographic/anatomical characteristics of brain AVMs in all patients. All case reports, review articles, and articles written in a language other than English without an available translation were excluded. Following retrieval of all articles that met the criteria for inclusion, we documented the institution and time period from which the patients were evaluated to avoid overlap and double counting of patients. In cases where there was overlap in patient populations between studies, only the larger or most detailed study was selected for our metaanalysis.

\section{Data Abstraction}

All data were abstracted by 1 reviewer with 6 years of experience in meta-analysis techniques. From each article, the following baseline data were collected: institution, study time period, imaging modality used to screen for brain AVMs, number of HHT patients, number of HHT patients with an AVM, sex, mean age/age group, region/ country of origin, HHT type, proportion of patients with multiple AVMs, AVM rupture status, AVM symptomatic status, Spetzler-Martin grade, deep venous drainage, AVM location, AVM size, and AVM angioarchitecture. Brain AVMs were categorized as 1) nidal AVMs (size $\geq 1$ $\mathrm{cm}), 2$ ) micro-AVMs (size $<1 \mathrm{~cm}$ ), and 3) pial arteriovenous fistulas (AVFs).

\section{Outcomes}

For the brain AVM prevalence meta-analysis, outcomes included overall AVM prevalence and AVM prevalence by sex, age group (adult vs pediatric), HHT type (HHT1 versus HHT2), and geographic region (North America, Europe, and Australia/Asia). We did not include the juvenile polyposis/HHT syndrome as part of our HHT type analysis because there were too few articles reporting prevalence of brain AVMs in this population. For the brain AVM clinical characteristics metaanalysis; the following 
outcomes were studied: AVM multiplicity, AVM rupture status, AVM symptomaticity status (overall symptomatic, symptomatic unruptured, overall asymptomatic), SpetzlerMartin grading scale, location, size less than $3 \mathrm{~cm}$, and AVM type.

\section{Risk of Bias}

Risk of bias was assessed by modifying the NewcastleOttawa grading scale. Factors that favored a lower risk of bias were the following: 1) prospective screening study of all patients with HHT, 2) clearly defined imaging protocol (i.e., MRI field strength, sequences, techniques, etc), 3) clear definition of patient groups (i.e., sex, age, HHT type, etc.), and 4) clear definition of AVM characteristics and clinical manifestations.

\section{Statistical Analysis}

We estimated from each cohort the cumulative prevalence and $95 \%$ confidence interval for each outcome. Rates of each outcome were pooled in meta-analysis across studies using the random-effects model. ${ }^{9}$ Anticipating heterogeneity in effect size between studies, we chose this model a priori because it incorporates both within-study variance and between-studies variance. Heterogeneity of treatment effect across studies was evaluated using the I-squared $\left(\mathrm{I}^{2}\right)$ statistic, in which an $\mathrm{I}^{2}$ value greater than $50 \%$ suggests substantial heterogeneity. ${ }^{21}$ Chi-square analysis was used to compare outcomes between groups when appropriate. Statistical analysis was performed using the software program OpenMeta[Analyst] (http://www.cebm. brown.edu/openmeta/).

\section{Results}

\section{Literature Search Results}

The initial literature search yielded 395 unique studies. Of these, 200 were excluded upon review of the abstract and titles alone. The remaining 195 full-text articles were then reviewed individually for inclusion in our study. Of these, 80 were excluded because they did not specifically screen for the presence of brain AVMs in the HHT population, an additional 66 articles were excluded because they did not meet the above-mentioned inclusion criteria. The remaining 49 articles were then further evaluated, and data were abstracted from them. Of these 49 articles, 10 were excluded due to definite overlap in patient population. In total, 39 articles were included in our study. Thirty articles reported AVM prevalence rates in the HHT population and 18 studies reported the characteristics of brain AVMs. Risk of bias was low or medium in 28 of the prevalence studies and 16 of the AVM characteristic studies. A flowchart summarizing our literature search process is provided in Fig. 1. A summary of included studies is provided in the Supplementary Tables.

\section{HHT AVM Prevalence Rates}

A summary of HHT AVM prevalence rates by patient group is provided in Table 1. In assessing overall brain AVM prevalence rates, a total of 5381 patients were included. The overall AVM prevalence rate was $10.4 \%$
(95\% CI 7.9\%-13.0\%). The forest plot is provided in Fig. 2 . There was no significant difference in the prevalence of brain AVMs in male $(8.5 \%, 95 \%$ CI $4.9 \%-12.0 \%)$ and female patients $(11.0 \%, 95 \%$ CI 5.9\%-16.1\%) $(\mathrm{p}=0.67)$. There was no significant difference in the prevalence of brain AVMs in pediatric $(12.2 \%, 95 \%$ CI $6.0 \%-18.3 \%)$ and adult patients $(9.0 \%, 95 \%$ CI $7.2 \%-10.8 \%)(p=0.08)$. Patients with HHT1 had an AVM prevalence rate of $13.4 \%$ (95\% CI 9.5\%-17.4\%), compared with a prevalence rate of $2.4 \%$ (95\% CI $1.0 \%-3.8 \%$ ) ( $<<0.0001)$ in the HHT2 group (Fig. 3). There was no statistically significant difference in AVM prevalence rates by population studied.

\section{HHT AVM Characteristics}

A summary of HHT brain AVM patient, anatomical, and angioarchitectural characteristics is provided in Table 2. Overall, $42.2 \%$ (95\% CI $25.8 \%-58.7 \%$ ) of HHT patients had multiple AVMs; $19.4 \%$ (95\% CI 12.2\%-26.7\%) of HHT AVM patients presented with rupture; and 55.2\% (95\% CI $38.3 \%-72.1 \%$ ) of HHT AVM patients had symptoms related to their AVMs.

A Spetzler-Martin grade of 2 or less was found in $81.3 \%$ (95\% CI $67.5 \%-95.2 \%)$ of the AVMs included in this meta-analysis; $86.9 \%$ (95\% CI $80.0 \%-93.9 \%$ ) of the AVMs were supratentorial in location and $85.0 \%(95 \%$ CI 76.7\%-93.2\%) were smaller than $3 \mathrm{~cm}$. Deep venous drainage was found in $15.8 \%$ (95\% CI $8.7 \%-22.8 \%$ ) of brain AVMs. The most common type of AVM was the nidal type $(62.3 \%, 95 \%$ CI $40.5 \%-84.1 \%)$ followed by micro-AVMs $(23.9 \%, 95 \%$ CI 8.8\%-39.0\%) and pial AVFs $(10.7 \%, 95 \%$ CI $5.1 \%-16.3 \%)$.

\section{Study Heterogeneity}

Heterogeneity of treatment effect across studies was evaluated using the $\mathrm{I}^{2}$ statistic, in which $\mathrm{I}^{2}>50 \%$ suggests substantial heterogeneity. ${ }^{21}$ For the prevalence studies, $\mathrm{I}^{2}$ values were above $50 \%$ for the overall prevalence estimate, prevalence in adult populations, and prevalence in European populations. $\mathrm{I}^{2}$ values were less than $50 \%$ indicating lack of substantial heterogeneity for the prevalence in pediatric populations, prevalence by gender groups, prevalence by HHT type, and prevalence rates in North American and Australian/Asian populations.

For the AVM characteristic studies, $\mathrm{I}^{2}$ values were above $50 \%$ for rupture status, symptoms on presentation, Spetzler-Martin grade of 2 or less, AVM size, AVM type, and AVM multiplicity. $\mathrm{I}^{2}$ values were less than $50 \%$ for AVM location.

\section{Discussion}

Our systematic review and meta-analysis of the literature on the prevalence and characteristics of brain AVMs in the HHT population demonstrated a number of interesting findings. The overall prevalence of brain AVMs in the HHT population was approximately $10 \%$ with no difference by sex, age, or population studied. Patients with HHT1 were significantly more likely to have brain AVMs than HHT2 patients were (13.4\% vs $2.4 \%$ ). AVM multiplicity was found in $42.2 \%$ of patients. Most of the HHT-associated AVMs were small and had a low 


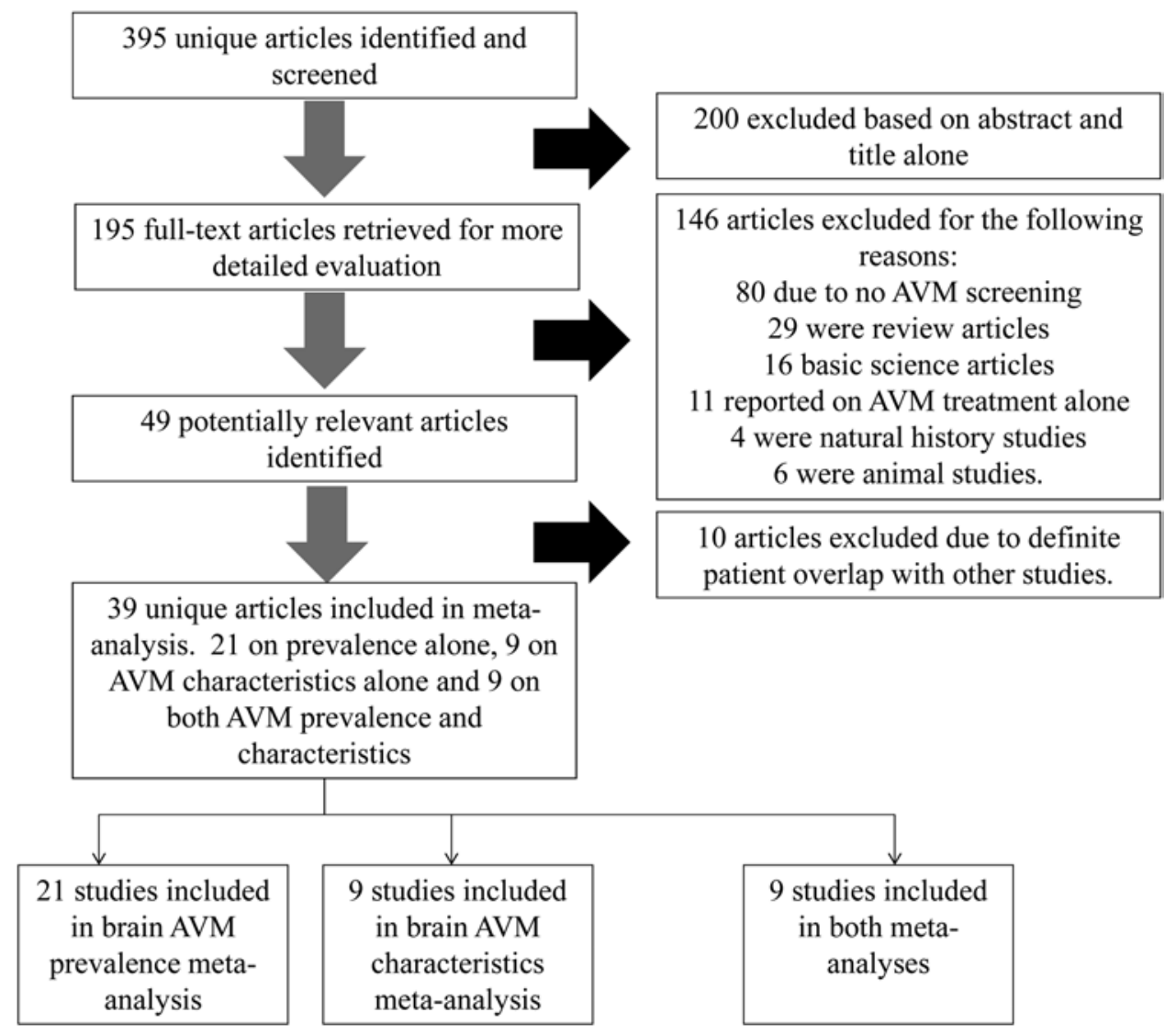

FIG. 1. Flow chart showing search strategy.

Spetzler-Martin grade. However, 20\% of these AVMs presented with rupture and nearly $50 \%$ of brain AVMs were symptomatic. These findings are important as they provide more information regarding the prevalence and clinical characteristics of brain AVMs in the HHT population.

Depending on the population being studied, the prevalence of brain AVMs in patients with HHT ranges from $2 \%$ to $20 \%$. ${ }^{1,2,4,8,12,30,38,39,42,43}$ Because of this wide variability, large studies such as ours are important as they provide a more comprehensive representation of the overall prevalence of brain AVMs in HHT. Smaller single-center studies are limited in their ability to detect differences in AVM prevalence rates between various patient populations (i.e., sex, age, etc.). Due to the large sample size of this meta-analysis, our study clearly demonstrates that there is no association between AVM prevalence and sex, age, or geographic location. As demonstrated in our study, in general, the rate of cerebral AVMs has been shown to be higher in patients with $E N G$ mutations than in those with $A L K 1$ (ACVRL1) mutations. ${ }^{4,12}$ In our meta-analysis, over $40 \%$ of patients had multiple AVMs. Lesion multiplicity is thought to be a hallmark of HHT, with prior studies showing that up to $60 \%$ of patients have at least 2 brain AVMs. ${ }^{7,28,29}$ Based on the high prevalence of cerebral AVMs in the HHT population, most experts agree that a screening MRI study is warranted for children and for adults who have not been previously screened. ${ }^{14}$
The lack of difference in the prevalence of brain AVMs by patient age group is important for a number of reasons. As there is no evidence of an increased prevalence of brain AVMs in adults compared with the pediatric age group, these findings suggest, but do not prove, that a vast majority of brain AVMs form very early in life and that

TABLE 1. Prevalence of AVMs in patients with HHT

\begin{tabular}{lccc}
\hline \multicolumn{1}{c}{ Variable } & Rate $(95 \% \mathrm{Cl})^{*}$ & Raw Data & p Value \\
\hline Overall & $10.4 \%(7.9-13.0 \%)$ & $708 / 5381$ & - \\
\hline Sex & & & 0.67 \\
\hline Male & $8.5 \%(4.9-12.0 \%)$ & $55 / 583$ & \\
\hline Female & $11.0 \%(5.9-16.1 \%)$ & $92 / 796$ & \\
\hline Age group & & 0.08 \\
\hline Pediatric & $12.2 \%(6.0-18.3 \%)$ & $41 / 315$ & \\
\hline Adult & $9.0 \%(7.2-10.8 \%)$ & $272 / 2803$ & \\
\hline HHT type & & $<0.0001$ \\
\hline HHT1 & $13.4 \%(9.5-17.4 \%)$ & $124 / 892$ & \\
\hline HHT2 & $2.4 \%(1.0-3.8 \%)$ & $22 / 555$ & \\
\hline Population & & 0.25 \\
\hline North American & $8.2 \%(6.6-9.8 \%)$ & $165 / 1862$ & \\
\hline European & $9.3 \%(4.2-14.3 \%)$ & $339 / 2647$ & \\
\hline Australian/Asian & $11.7 \%(8.2-15.2 \%)$ & $39 / 317$ & \\
\hline * Results of meta-anasis &
\end{tabular}

\footnotetext{
${ }^{*}$ Results of meta-analysis.
} 


\section{Studies}

Krings, 2015

Edwards, 2011

Paez, 2013

Lesca, 2007

Kim, 2011

Woodall, 2014

Fagnou, 2009

Haq Faheem, 2013

Haq Faheem, 20131

Brinjikji, 2016 ${ }^{7}$

Ni Bhuachalla, 2010

Kjeldsen et al, 2005

Torring, 2014

Komiyama, 2014

Folz, 2004

Salaria, 2014

Massman, 2013

Anderson, 2014

Mei-Zahav, 2011

Drouet, 2012

Coduras, 2013

Giordano, 2013

Sabba, 2007

Willemse, 2000

Letteboer, 2006

Bossler, 2006

Bayrak-Toydemir, 2006

Fulbright, 1998

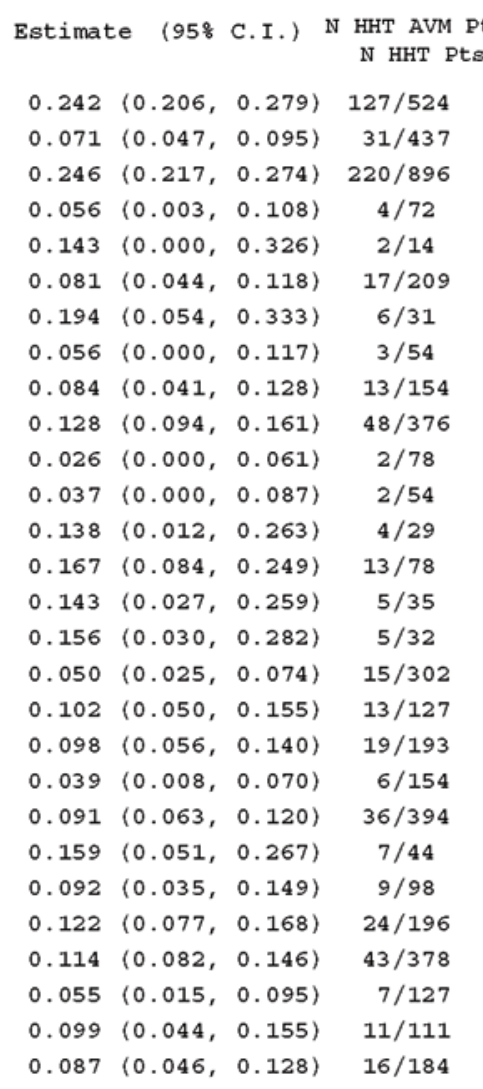

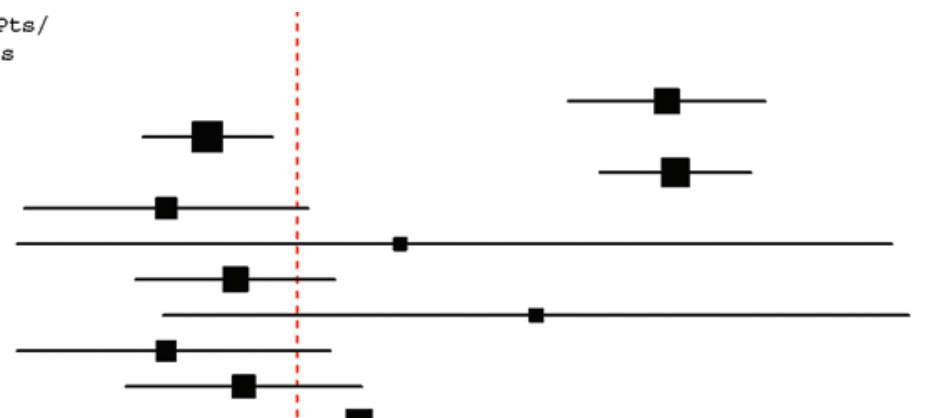

Overall (I^2=88.94\%, P< 0.001) $0.104 \quad(0.079,0.130) \quad 708 / 5381$

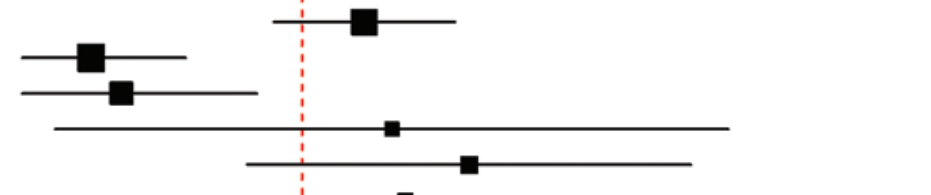

FIG. 2. Forest plot of overall prevalence. $\mathrm{N}$ = number of; $p t s=$ patients. Figure is available in color online only.

the rate of de novo formation of brain AVMs in the HHT population is exceedingly low. While there have been case reports demonstrating de novo brain AVM formation in this population, it has not been shown in a large-scale prospective screening study. ${ }^{11,30,33,46}$ These findings, along with ours, which demonstrate no age-related increase in AVM prevalence, support the notion that repeat screening for brain AVMs is likely not clinically indicated. However,

\section{Studies}

\section{Edwards, 2011}

Lesca, 2007

Kim, 2011

Brinjikji, 2016 ${ }^{7}$

Kjeldsen, 2005

Torring, 2014

Komiyama, 2014

Giordano, 2013

Sabba, 2007

Letteboer, 2006

Bossler, 2006

Bayrak-Toydemir, 2006

\begin{tabular}{|c|c|c|c|c|}
\hline stimate & $=1958$ & C.I.) & $\begin{array}{c}\text { HHT1 } \\
\text { N AVM } \\
\text { /N Pts }\end{array}$ & $\begin{array}{l}\text { HHT2 } \\
\text { N AVM } \\
\text { /N pts }\end{array}$ \\
\hline 1.995 & (0.868, & $4.583)$ & $23 / 232$ & $8 / 153$ \\
\hline 2.400 & (0.316, & $18.241)$ & $2 / 22$ & $2 / 50$ \\
\hline 2.692 & (0.099, & $73.195)$ & $2 / 8$ & $0 / 3$ \\
\hline 1.714 & $(0.592$, & $4.964)$ & $12 / 61$ & $6 / 48$ \\
\hline 0.395 & $(0.023$, & $6.726)$ & $1 / 39$ & $1 / 16$ \\
\hline 0.857 & $(0.065$, & $11.357)$ & $2 / 16$ & $1 / 7$ \\
\hline 7.385 & (0.902, & $60.450)$ & $12 / 51$ & $1 / 25$ \\
\hline 7.875 & (0.860, & $72.122)$ & $6 / 22$ & $1 / 22$ \\
\hline 30.565 & (1.724, & , 541.991) & $9 / 43$ & $0 / 55$ \\
\hline 12.838 & (1.733, & 95.1221 & $38 / 260$ & $1 / 76$ \\
\hline 10.745 & $(0.600$, & , 192.450$\rangle$ & $7 / 77$ & $0 / 50$ \\
\hline 9.608 & (1.185, & $77.887)$ & $10 / 61$ & $1 / 50$ \\
\hline
\end{tabular}

Overall $\left(I^{\wedge} 2=14.03 \%, P=0.307\right)$

3.196 (1.794,

5.694) $124 / 892$

$22 / 555$

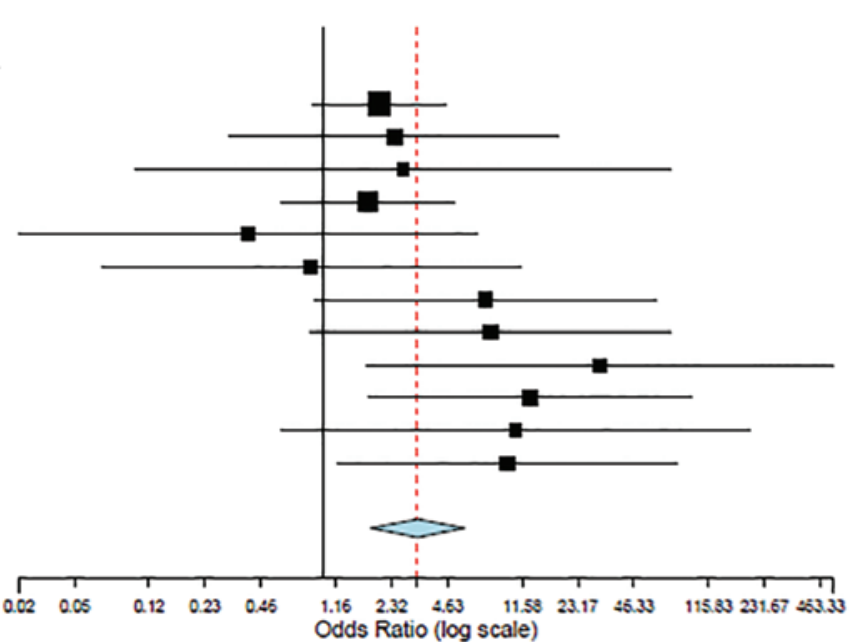

FIG. 3. Forest plot of brain AVM prevalence by HHT type (HHT1 vs HHT2). Figure is available in color online only. 
TABLE 2. Brain AVM characteristics

\begin{tabular}{lcc}
\hline \multicolumn{1}{c}{ Characteristic } & Rate $(95 \%$ Cl) & Raw Numbers \\
\hline Patients w/ multiple AVMs & $42.2 \%(25.8-58.7 \%)$ & $173 / 472$ \\
\hline Rupture status & & \\
\hline Ruptured & $19.4 \%(12.2-26.7 \%)$ & $85 / 426$ \\
\hline Unruptured & $80.6 \%(73.3-87.8 \%)$ & $341 / 426$ \\
\hline Symptomaticity status & & \\
\hline Symptomatic & $55.2 \%(38.3-72.1 \%)$ & $156 / 341$ \\
\hline Symptomatic \& unruptured & $26.1 \%(14.0-38.3 \%)$ & $80 / 341$ \\
\hline Asymptomatic & $40.7 \%(24.4-57.0 \%)$ & $185 / 341$ \\
\hline Spetzler-Martin grade & \multicolumn{3}{l}{} \\
\hline 1 & $44.3 \%(31.8-56.9 \%)$ & $90 / 217$ \\
\hline 2 & $30.7 \%(14.7-46.7 \%)$ & $76 / 217$ \\
\hline 3 & $19.0 \%(2.9-35.2 \%)$ & $46 / 217$ \\
\hline 4 & $1.2 \%(0.0-2.7 \%)$ & $3 / 217$ \\
\hline 5 & $1.2 \%(0.0-2.6 \%)$ & $2 / 217$ \\
\hline Spetzler-Martin grade $\leq 2$ & $81.3 \%(67.5-95.2 \%)$ & $182 / 234$ \\
\hline Supratentorial Location & $86.9 \%(80.0-93.9 \%)$ & $376 / 440$ \\
\hline Eloquent location & $51.7 \%(39.4-63.9 \%)$ & $115 / 226$ \\
\hline Deep venous drainage & $15.8 \%(8.7-22.8 \%)$ & $54 / 401$ \\
\hline Size <3 cm & $85.0 \%(76.7-93.2 \%)$ & $299 / 366$ \\
\hline AVM type & \multicolumn{2}{l}{$61 / 473$} \\
\hline Nidal & $62.3 \%(40.5-84.1 \%)$ & $232 / 473$ \\
\hline Micro-AVM & $23.9 \%(8.8-39.0 \%)$ & $180 / 473$ \\
\hline Pial AVF & $10.7 \%(5.1-16.3 \%)$ & 6 \\
\hline
\end{tabular}

* Results of meta-analysis.

additional prospective studies are needed to confirm these findings.

Most experts agree that patients with HHT should be screened for cerebral vascular malformations at least once during their clinical evaluation. Those who disagree with this recommendation generally cite lack of evidence for benefit of screening in children and lack of evidence of treatment efficacy for asymptomatic cerebral vascular malformations in children. Our findings, however, suggest that approximately $20 \%$ of HHT patients with brain AVMs will suffer from AVM-related hemorrhage, and about 50\% of HHT patients with brain AVMs have symptoms related to the brain AVM, including headache, seizure, and/or focal neurological deficit. Given the high proportion of patients who end up experiencing symptoms or hemorrhage related to their brain AVMs, our study provides additional supportive evidence for those who advocate screening in both the adult and pediatric population. Ultimately, the decision to treat these lesions should be made on a caseby-case basis. However, there is growing evidence in the literature that AVMs in patients with HHT can be treated safely with surgical, endovascular and radiosurgical techniques..$^{19,26,27,34,45,51}$

Our study demonstrated a number of interesting findings regarding the angioarchitecture of brain AVMs in the HHT population, especially when compared with the sporadic AVM population (Table 3). First, a vast majority ( $>80 \%$ ) of the these AVMs in patients with HHT were smaller than $3 \mathrm{~cm}$, supratentorial, and had a Spetzler-Mar-
TABLE 3. Comparison of HHT-associated AVMs and sporadic AVMs

\begin{tabular}{lcc}
\hline \multicolumn{1}{c}{ Characteristic } & Sporadic AVMs* & HHT AVMs \\
\hline Patient age at diagnosis, yrs & $30-40$ & $30-40$ \\
\hline Sex distribution, M/F & $1: 1$ & $1: 1$ \\
\hline Hemorrhage on presentation & $40-50 \%$ & $20 \%$ \\
\hline Multiplicity & $1 \%$ & $42 \%$ \\
\hline Size $>3 \mathrm{~cm}$ & $50 \%$ & $15 \%$ \\
\hline Deep venous drainage & $20 \%$ & $15 \%$ \\
\hline Location & & \\
\hline$\quad$ Supratentorial & $90 \%$ & $87 \%$ \\
\hline$\quad$ Infratentorial & $10 \%$ & $13 \%$ \\
\hline $\begin{array}{l}\text { Type } \\
\quad \text { Nidal }\end{array}$ & $98 \%$ & $62 \%$ \\
\hline$\quad$ Pial & $2 \%$ & $11 \%$ \\
\hline $\begin{array}{l}\text { Micro-AVM or capillary vascular } \\
\text { malformation }\end{array}$ & $\mathrm{NA}$ & $24 \%$ \\
\hline $\begin{array}{l}\text { NA }=\text { not available. } \\
\text { * Data on sporadic AVM characteristics were obtained from individual patient } \\
\text { meta-analysis published by Kim et al. }{ }^{22}\end{array}$ &
\end{tabular}

tin grade of 2 or less. However, in the sporadic AVM population, the mean AVM nidus size is about $3 \mathrm{~cm}$ and the median Spetzler-Martin score is 3, suggesting that at least $50 \%$ of sporadic AVMs have an Spetzler-Martin grade of 3 or higher. ${ }^{22}$ A high proportion of AVMs in the HHT population (approximately 10\%) are direct pial AVFs. Pial AVFs are defined by a lack of a nidus between the feeding artery and draining vein-i.e., a single hole with a pouch with direct arteriovenous shunting..$^{28,29}$ These lesions are exceedingly rare in the patients with sporadic AVMs, accounting for less than $2 \%$ of lesions..$^{18}$ Nidal AVMs and micro-AVMs/capillary vascular malformations made up the majority of AVMs in this meta-analysis. Nidal AVMs are arteriovenous connections with an intervening nidus with the presence of a shunt or early draining vein., ${ }^{7,28}$ About half of these lesions do present with symptoms, and in a substantial proportion of cases, the AVM has ruptured. Micro-AVMs are also known as capillary malformations. These lesions lack shunting on angiography and have no dilated feeding arteries or veins. Rather they are characterized by a blush of abnormal vessels in the capillary phase. ${ }^{7,28,29}$ In general, micro-AVMs are thought to be benign and asymptomatic and, like pial AVFs, are likely exceedingly uncommon in patients with sporadic AVMs.

A few prior studies have examined the natural history of brain AVMs in the HHT population. These studies are limited by the fact that AVMs that present as symptomatic or have more aggressive angioarchitectural features are more likely to be managed surgically and thus would not be included in such studies. In a Dutch study of 29 patients with cerebral vascular malformations, including 22 patients with AVMs, a bleeding risk of $0.4 \%-0.7 \%$ was found for AVMs. ${ }^{48}$ However, the natural history calculations were based on the age of the patient, with the assumption that the AVMs were congenital, rather than 
the time of follow-up from discovery of the AVM. A recently published study of 153 HHT brain AVM patients from the Brain Vascular Malformation Consortium HHT Investigator Group demonstrated an overall bleeding rate of $1 \%$ per year, with a rupture rate of $0.4 \%$ per year $(95 \%$ CI $0.1 \%-1.7 \%$ ) for unruptured AVMs and $10 \%$ per year for previously ruptured AVMs (95\% CI 3.3\%-31.2\%). A smaller, single-center study of 12 HHT patients with 23 AVMs which were followed found a rupture rate of $1.3 \%$ per patient year and $0.7 \%$ per AVM year, but a substantial proportion of these lesions were small microAVMs, lesions that are almost universally benign. ${ }^{50}$ Two small studies have examined the natural history of these microAVMs. A study of 22 patients with 42 capillary vascular malformations/micro-AVMs found that none of these lesions ruptured or became symptomatic after over 200 lesion-years of follow-up. ${ }^{5}$ In another study, Matsubara et al. also found that none of the micro-AVMs in their series had ruptured on follow-up. ${ }^{36}$

\section{Limitations}

Our study has limitations. First, $\mathrm{I}^{2}$ values were above $50 \%$ for many of the estimates, suggesting substantial heterogeneity in the reporting of outcomes. For the prevalence study, many of the studies were retrospective single-institution series as opposed to prospective screening studies. It is possible that these studies could overestimate the proportion of AVMs due to selection biases. Various techniques were used in screening patients for AVMs in these series, including MRI, MR angiography (MRA), CT angiography (CTA), and digital subtraction angiography (DSA). It is well established that DSA is the most sensitive imaging modality for detection of brain AVMs. In fact, many micro-AVMs may be undetectable on MRI or MRA and may only be seen on DSA. Another limitation to this meta-analysis is the fact that it is possible that there was overlap in the patient populations in some of the studies, even though the search strategy was designed to eliminate double counting as much as possible. Because many studies lumped multiple AVM types (i.e., micro-AVM, nidal AVM, capillary vascular malformation, and pial AVF) in their size measurements, we are unable to determine the mean nidus size of each individual type of AVM.

\section{Conclusions}

Our systematic review and meta-analysis of AVM prevalence and characteristics in the HHT population demonstrated that these lesions are found in approximately $10 \%$ of HHT patients. Patients with HHT1 were significantly more likely to have brain AVMs than those with HHT2. Roughly half of brain AVMs in the HHT population are symptomatic and $80 \%$ have a Spetzler-Martin grade of 2 or less. Sex, age, and geographic region were not associated with AVM prevalence. Further studies are needed to determine the ideal screening and treatment protocols for brain AVMs in the HHT population.

\section{References}

1. Al-Saleh S, Mei-Zahav M, Faughnan ME, MacLusky IB,
Carpenter S, Letarte M, et al: Screening for pulmonary and cerebral arteriovenous malformations in children with hereditary haemorrhagic telangiectasia. Eur Respir J 34:875-881, 2009

2. Anderson JL, White AJ: Utility of repeat surveillance neuroimaging for cerebral arteriovenous malformations in children with hereditary hemorrhagic telangiectasia. Ann Neurol 76 (Suppl 18):S239, 2014 (Abstract)

3. Bayrak-Toydemir P, McDonald J, Markewitz B, Lewin S, Miller F, Chou LS, et al: Genotype-phenotype correlation in hereditary hemorrhagic telangiectasia: mutations and manifestations. Am J Med Genet A 140:463-470, 2006

4. Bossler AD, Richards J, George C, Godmilow L, Ganguly A: Novel mutations in ENG and ACVRL1 identified in a series of 200 individuals undergoing clinical genetic testing for hereditary hemorrhagic telangiectasia (HHT): Correlation of genotype with phenotype. Hum Mutat 27:667-675, 2006

5. Brinjikji W, Iyer VN, Lanzino G, Thielen KR, Wood CP: Natural history of brain capillary vascular malformations in hereditary hemorrhagic telangiectasia patients. J Neurointerv Surg [epub ahead of print], 2016

6. Brinjikji W, Iyer VN, Sorenson T, Lanzino G: Cerebrovascular manifestations of hereditary hemorrhagic telangiectasia. Stroke 46:3329-3337, 2015

7. Brinjikji W, Iyer VN, Yamaki V, Lanzino G, Cloft HJ, Thielen KR, et al: Neurovascular manifestations of hereditary hemorrhagic telangiectasia: a consecutive series of 376 patients during 15 years. AJNR Am J Neuroradiol [epub ahead of print], 2016

8. Coduras A, Amado C, Calvo N, Velasco L, Pascual C, Portilla R, et al: Prevalence of hereditary hemorrhagic telangiectasia (HHT) and genotype-phenotype correlation in Spain. Eur J Intern Med 24:e183-e184, 2013

9. DerSimonian R, Laird N: Meta-analysis in clinical trials. Control Clin Trials 7:177-188, 1986

10. Drouet T, Muresan IP, Maro B, Carette MF, Alamowitch S: Neurologic phenotype associated with hereditary haemorrhagic telangiectasia in a monocentric cohort of 154 patients. Stroke 43 (2 Meeting Abstracts):A2421, 2012 (Abstract)

11. Du R, Hashimoto T, Tihan T, Young WL, Perry V, Lawton MT: Growth and regression of arteriovenous malformations in a patient with hereditary hemorrhagic telangiectasia. Case report. J Neurosurg 106:470-477, 2007

12. Edwards C, Vethanayagam D, Wilcox P, Klatt R, Horsburgh $\mathrm{S}$, Miller L, et al: Genotype-phenotype correlations of canadians with hereditary hemorrhagic telangiectasia. Hematol Rep 3:28, 2011

13. Fagnou C, Chinet TH, Sznajder M, Blivet S, Blondel JH, Bourgault-Villada I, et al: Clinical manifestations of Rendu Osler Weber disease in children. Haematologica Meeting Reports 3:51, 2009

14. Faughnan ME, Palda VA, Garcia-Tsao G, Geisthoff UW, McDonald J, Proctor DD, et al: International guidelines for the diagnosis and management of hereditary haemorrhagic telangiectasia. J Med Genet 48:73-87, 2011

15. Folz BJ, Wollstein AC, Alfke H, Dunne AA, Lippert $\mathrm{BM}$, Gorg K, et al: The value of screening for multiple arterio-venous malformations in hereditary hemorrhagic telangiectasia: a diagnostic study. Eur Arch Otorhinolaryngol 261:509-516, 2004

16. Fulbright RK, Chaloupka JC, Putman CM, Sze GK, Merriam MM, Lee GK, et al: MR of hereditary hemorrhagic telangiectasia: prevalence and spectrum of cerebrovascular malformations. AJNR Am J Neuroradiol 19:477-484, 1998

17. Giordano P, Lenato GM, Suppressa P, Lastella P, Dicuonzo F, Chiumarulo L, et al: Hereditary hemorrhagic telangiectasia: arteriovenous malformations in children. J Pediat 163:179186, 186.e171-186.e173, 2013 
18. Halbach VV, Higashida RT, Hieshima GB, Hardin CW, Dowd CF, Barnwell SL: Transarterial occlusion of solitary intracerebral arteriovenous fistulas. AJNR: Am J Neuroradiol 10:747-752, 1989

19. Han C, Choe SW, Kim YH, Acharya AP, Keselowsky BG, Sorg BS, et al: VEGF neutralization can prevent and normalize arteriovenous malformations in an animal model for hereditary hemorrhagic telangiectasia 2. Angiogenesis 17:823-830, 2014

20. Haq Faheem UL, Robinson G, Merlo CA, Collaco JM, Terry P, Mitchell S: HHT center of excellence at Johns Hopkins Hospital-organization, screening, and treatment results in children and adults 2009-2013. Hematol Rep 5 (1 Suppl):69-70, 2013 (Abstract)

21. Higgins JP, Thompson SG, Deeks JJ, Altman DG: Measuring inconsistency in meta-analyses. BMJ 327:557-560, 2003

22. Kim H, Al-Shahi Salman R, McCulloch CE, Stapf C, Young WL: Untreated brain arteriovenous malformation: patientlevel meta-analysis of hemorrhage predictors. Neurology 83:590-597, 2014

23. Kim MJ, Kim ST, Lee HD, Lee KY, Seo J, Lee JB, et al: Clinical and genetic analyses of three Korean families with hereditary hemorrhagic telangiectasia. BMC Med Genet 12:130, 2011

24. Kjeldsen AD, Torring PM, Nissen H, Andersen PE: Cerebral abscesses among Danish patients with hereditary haemorrhagic telangiectasia. Acta Neurol Scand 129:192197, 2014

25. Komiyama M, Ishiguro T, Yamada O, Morisaki H, Morisaki $\mathrm{T}$ : Hereditary hemorrhagic telangiectasia in Japanese patients. J Hum Genet 59:37-41, 2014

26. Krings T, Chng SM, Ozanne A, Alvarez H, Rodesch G, Lasjaunias PL: Hereditary haemorrhagic telangiectasia in children. Endovascular treatment of neurovascular malformations. Results in 31 patients. Interv Neuroradiol 11:13-23, 2005

27. Krings T, Chng SM, Ozanne A, Alvarez H, Rodesch G, Lasjaunias PL: Hereditary hemorrhagic telangiectasia in children: endovascular treatment of neurovascular malformations: results in 31 patients. Neuroradiology 47:946-954, 2005

28. Krings T, Kim H, Power S, Nelson J, Faughnan ME, Young WL, et al: Neurovascular manifestations in hereditary hemorrhagic telangiectasia: imaging features and genotypephenotype correlations. AJNR Am J Neuroradiol 36:863870,2015

29. Krings T, Ozanne A, Chng SM, Alvarez H, Rodesch G, Lasjaunias PL: Neurovascular phenotypes in hereditary haemorrhagic telangiectasia patients according to age. Review of 50 consecutive patients aged 1 day-60 years. Neuroradiology 47:711-720, 2005

30. Latino GA, Al-Saleh S, Carpenter S, Ratjen F: The diagnostic yield of rescreening for arteriovenous malformations in children with hereditary hemorrhagic telangiectasia. J Pediatr 165:197-199, 2014

31. Lesca G, Olivieri C, Burnichon N, Pagella F, Carette MF, Gilbert-Dussardier B, et al: Genotype-phenotype correlations in hereditary hemorrhagic telangiectasia: data from the French-Italian HHT network. Genet Med 9:14-22, 2007

32. Letteboer TG, Mager JJ, Snijder RJ, Koeleman BP, Lindhout D, Ploos van Amstel JK, et al: Genotype-phenotype relationship in hereditary haemorrhagic telangiectasia. J Med Genet 43:371-377, 2006

33. Leung KM, Agid R, terBrugge K: Spontaneous regression of a cerebral arteriovenous malformation in a child with hereditary hemorrhagic telangiectasia. Case report. J Neurosurg 105 (5 Suppl):428-431, 2006

34. Maarouf M, Runge M, Kocher M, Zahringer M, Treuer $\mathrm{H}$, Sturm V: Radiosurgery for cerebral arteriovenous malformations in hereditary hemorrhagic telangiectasia. Neurology 63:367-369, 2004

35. Massmann A, Geisthoff U, Buecker A, Schneider GK: MRI and mRA for the detection of CAVm in patients with HHT. Hematol Rep 5:19-20, 2013

36. Matsubara S, Mandzia JL, terBrugge K, Willinsky RA, Faughnan ME: Angiographic and clinical characteristics of patients with cerebral arteriovenous malformations associated with hereditary hemorrhagic telangiectasia. AJNR Am J Neuroradiol 21:1016-1020, 2000 (Erratum in AJNR Am J Neuroradiol 22:1446, 2001)

37. McDonald J, Bayrak-Toydemir P, Pyeritz RE: Hereditary hemorrhagic telangiectasia: an overview of diagnosis, management, and pathogenesis. Genet Med 13:607-616, 2011

38. Mei-Zahav M, Goldschmidt N, Metzger S, Yaniv E, Blau H, Birk E, et al: Clinical and genetic characteristics of patients with HHT-the National Israeli Center experience. Hematol Rep 3:41, 2011

39. Ni Bhuachalla CF, TM OC, Murphy M, Colwell N, Brady A: Experience of the Irish National Centre for hereditary haemorrhagic telangiectasia 2003-2008. Resp Med 104:1218-1224, 2010

40. Paez C, Giraud S, Lesca G, Decullier E, Babin E, Carette MF, et al: Genotype-phenotype correlations in hereditary haemorrhagic telangiectasia. Data of the French RenduOsler-Weber cohort. Hematol Rep 5:12-13, 2013

41. Sabba C, Pasculli G, Lenato GM, Suppressa P, Lastella P, Memeo M, et al: Hereditary hemorrhagic telangiectasia: clinical features in ENG and ALK1 mutation carriers. J Thromb Haemost 5:1149-1157, 2007

42. Salaria M, Taylor J, Bogwitz M, Winship I: Hereditary haemorrhagic telangiectasia, an Australian cohort: clinical and investigative features. Intern Med J 44:639-644, 2014

43. Saleh M, Carter MT, Latino GA, Dirks P, Ratjen F: Brain arteriovenous malformations in patients with hereditary hemorrhagic telangiectasia: clinical presentation and anatomical distribution. Pediatr Neurol 49:445-450, 2013

44. Shovlin CL, Guttmacher AE, Buscarini E, Faughnan ME, Hyland RH, Westermann CJ, et al: Diagnostic criteria for hereditary hemorrhagic telangiectasia (Rendu-Osler-Weber syndrome). Am J Med Genet 91:66-67, 2000

45. Skrinjarić-Cincar S, Petrović G, Fuštar Bosanac V, Fijačko V, Hećimović I: Complications of pulmonary AVMs in a patient with Rendu-Osler-Weber disease. Coll Antropol 38:10711075,2014

46. Suppressa P, Giordano P, Lenato GM, Sangerardi M, Lastella P, Quaranta D, et al: Longitudinal study of natural history of arteriovenous malformations in evolutionary age of hereditary haemorrhagic telangiectasia. Hematol Rep 5:45, 2013

47. Tørring PM, Brusgaard K, Ousager LB, Andersen PE, Kjeldsen AD: National mutation study among Danish patients with hereditary haemorrhagic telangiectasia. Clin Genet 86:123-133, 2014

48. Willemse RB, Mager JJ, Westermann CJ, Overtoom TT, Mauser H, Wolbers JG: Bleeding risk of cerebrovascular malformations in hereditary hemorrhagic telangiectasia. $\mathbf{J}$ Neurosurg 92:779-784, 2000

49. Woodall MN, McGettigan M, Figueroa R, Gossage JR, Alleyne $\mathrm{CH}$ Jr: Cerebral vascular malformations in hereditary hemorrhagic telangiectasia. J Neurosurg 120:8792, 2014

50. Yang W, Liu A, Hung A, Braileanu M, Wang JY, Caplan JM, et al: Lower risk of intracranial arteriovenous malformation hemorrhage in patients with hereditary hemorrhagic telangiectasia. Neurosurgery 78:684-693, 2016

51. Young L: Lumpers versus splitters: Is hereditary hemorrhagic telangiectasia a biological model of sporadic brain arteriovenous malformation? Hematol Rep 3:10, 2011 


\section{Disclosures}

Dr. Lanzino reports a consultant relationship with Medtronic.

\section{Author Contributions}

Conception and design: all authors. Acquisition of data: Brinjikji, Iyer. Analysis and interpretation of data: Brinjikji, Iyer, Lanzino. Drafting the article: all authors. Critically revising the article: all authors. Reviewed submitted version of manuscript: all authors. Approved the final version of the manuscript on behalf of all authors: Brinjikji. Statistical analysis: Brinjikji. Administrative/ technical/material support: Brinjikji. Study supervision: Brinjikji, Lanzino.

\section{Supplemental Information}

Online-Only Content

Supplemental material is available with the online version of the article.

Supplementary Tables. https://thejns.org/doi/suppl/10.3171/ 2016.7.JNS16847.

\section{Correspondence}

Waleed Brinjikji, Department of Radiology, Mayo Clinic, 200 1st St. SW, Rochester, MN 55905. email: brinjikji.waleed@mayo. edu. 